\title{
Parenting Gizi Berbasis WhatsApp untuk Meningkatkan Pengetahuan Ibu dalam Mengoptimalkan 1000 Hari Pertama Kehidupan
}

\author{
(WhatsApp-Based Nutrition Parenting to Increase Maternal Knowledge in \\ Optimizing the First 1000 Days of Life)
}

\author{
Shefa Dwijayanti Ramadani * \\ Pendidikan Biologi, FKIP, Universitas Islam Madura \\ Kompleks PP Miftahul Ulum Bettet Pamekasan
}

\begin{abstract}
ARTICLE INFO
ABSTRAK

Article history

Received : 26 Februari 2021

Revised : 29 April 2021

Accepted : 08 Juni 2021

DOI :

https://doi.org/10.33366/jast.v5i1

.2300

Keywords : first 1000 days of life; maternal knowledge; whatsapp based parenting

*e-mail corresponding author : shefadwijayanti@gmail.com

Nutrisi prenatal ibu dan nutrisi anak dalam 2 tahun pertama kehidupan (1000 Hari Pertama Kehidupan) merupakan faktor penting dalam perkembangan saraf anak dan kualitas hidup anak di masa depan. Sayangnya, tidak semua ibu memiliki pengetahuan yang mencukupi untuk mengoptimalkan periode penting pertumbuhan. Program pengabdian kepada masyarakat ini bertujuan untuk meningkatkan pengetahuan ibu dalam kelompok PKK Perum Tlanakan Indah Kabupaten Pamekasan dalam mengoptimalkan 1000 Hari Pertama Kehidupan (HPK). Kegiatan parenting gizi dilaksanakan melalui penyuluhan berbasis WhatssApp group. Hasil analisis data melalui gain score menunjukkan bahwa terdapat peningkatan pengetahuan ibu sebesar $82,22 \%$ atau dalam kategori sedang. Dengan demikian, hasil kegiatan ini diharapkan bisa menjadi rekomendasi bagi pihak terkait untuk memberikan edukasi di wilayah kerjanya guna mendukung optimalisasi $1000 \mathrm{HPK}$.
\end{abstract}

\section{PENERBIT}

\section{UNITRI PRESS}

Jl. Telagawarna, Tlogomas-

Malang, 65144, Telp/Fax: $0341-565500$

\begin{tabular}{l} 
CC) () \\
This is an open access article under \\
the Creative Commons \\
Attribution-ShareAlike $\mathbf{4 . 0}$ \\
\hline International License. Any further \\
distribution of this work must \\
maintain attribution to the author(s) \\
and the title of the work, journal \\
citation and DOI. CC-BY-SA
\end{tabular}

\section{ABSTRACT}

Maternal prenatal nutrition and a child's nutrition in the first two years of life (First 1000 Days of Life) are important factors in children's neurodevelopment and quality of life for children in the future. Unfortunately, not all mothers have sufficient knowledge to optimize this vital period of growth. This community service program aimed to increase maternal knowledge in optimizing the first 1000 days of life in the PKK group of Perum Tlanakan Indah, Pamekasan Regency. Nutrition parenting activities were carried out through WhatsApp group-based counseling. The results of data analysis using gain score showed an increase in maternal knowledge by $82,22 \%$ or the moderate category. The result of this program was expected to be a recommendation for the authority to provide education in their working area and support the optimization of $1000 \mathrm{HPK}$.

Cara Mengutip : Ramadani, S. D. (2021). Parenting Gizi Berbasis WhatsApp untuk Meningkatkan Pengetahuan Ibu dalam Mengoptimalkan 1000 Hari Pertama Kehidupan. JAST : Jurnal Aplikasi Sains dan Teknologi, 5(1), 21-31. doi:https://doi.org/10.33366/jast.v5i1.2300 


\section{PENDAHULUAN}

Perkembangan saraf yang sehat dan normal adalah proses kompleks yang melibatkan perubahan seluler dan struktural di otak yang berlangsung dalam urutan tertentu [1]. Periode paling aktif dari perkembangan neurologis terjadi dalam 1000 Hari Pertama Kehidupan (1000 HPK), yakni periode yang dimulai saat pembuahan dan berakhir pada awal tahun ketiga setelah melahirkan [2], atau dimulai sejak bayi dalam kandungan sampai berusia dua tahun [3]. Periode ini sering disebut sebagai periode emas dalam mempengaruhi hasil akhir anak, dan salah satu aspek penting yang harus diperhatikan yaitu pemenuhan gizi secara tepat.

Gizi yang cukup diperlukan untuk perkembangan otak yang normal. Nutrisi sangat penting selama kehamilan dan masa bayi, yang merupakan periode penting untuk pembentukan otak, meletakkan dasar bagi perkembangan keterampilan kognitif, motorik, dan sosio-emosional sepanjang masa kanak-kanak hingga dewasa. Kegagalan untuk menyediakan nutrisi utama selama periode kritis perkembangan otak dapat mengakibatkan kerusakan atau terhambatnya pertumbuhan yang tidak bisa diperbaiki di masa kehidupan selanjutnya. Kekurangan gizi selama kehamilan dan masa bayi juga kemungkinan besar akan memengaruhi kognisi, perilaku, dan produktivitas selama tahun-tahun di masa sekolah hingga waktu dewasa [1]. Dampak buruk yang ditimbulkan dari kekurangan gizi, dalam jangka pendek yaitu menyebabkan terganggunya perkembangan otak, kecerdasan, gangguan pertumbuhan fisik, dan gangguan dalam metabolisme tubuh. Sementara itu, dalam jangka panjang kondisi tersebut berdampak buruk pada menurunnya kemampuan kognitif dan prestasi belajar, menurunnya kekebalan tubuh, dan resiko tinggi untuk munculnya penyakit seperti diabetes, kegemukan, penyakit jantung dan pembuluh darah, kanker, stroke, dan disabilitas pada usia tua [4]-[5]. Resiko ini tentu dapat dihindari dengan memperhatikan nutrisi awal pada masa bayi, jenis laktasi, dan cara serta waktu makanan padat diperkenalkan [4]. Oleh karenanya, pemahaman yang baik tentang nutrisi pada periode awal kehidupan memiliki manfaat jangka panjang dan luas bagi individu dan masyarakat.

Masalah gizi pada anak tidak hanya disebabkan oleh faktor ekonomi tetapi juga karena kurangnya pengetahuan orang tua terutama ibu tentang gizi dan aspek psikososial seperti poa asuh (parenting). Hoffman, dkk. [6] mengungkapkan bahwa status gizi anak berkaitan dengan pola asuh orang tua; yakni makanan sehat atau tidak sehat yang dikonsumsi oleh anak adalah bergantung dari pola asuh orang tua.

Orang tua terutama ibu menjadi aktor utama dalam mengoptimalisasi tumbuh kembang anak. Proses tumbuh kembang anak dapat berlangsung optimal dengan dukungan lingkungan dan proses belajar berkelanjutan dalam jangka waktu tertentu. Dukungan lingkungan yang dimaksud antara lain pemenuhan kecukupan gizi dan stimulasi yang sesuai. Sayangnya, tidak semua ibu memiliki pengetahuan dan pemahaman yang mendalam tentang pentingnya pemenuhan nutrisi anak untuk optimalisasi 1000 HPK. 
Hasil analisis situasi mengungkap persoalan mitra Pengabdian pada Masyarakat (PPM) dalam hal ini yaitu ibu-ibu yang tergabung dalam kelompok PKK Perum Tlanakan Indah belum memiliki pengetahuan yang mencukupi dalam mengoptimalkan 1000 HPK. Beberapa permasalaham yang sering dihadapi ibu dalam upaya pemenuhan gizi anak antara lain kurangnya pengetahuan tentang teknik produksi dan manajemen asi yang berdampak terhadap kegagalan pemberian asi ekslusif, permasalahan dalam pemenuhan gizi pada anak susah makan, serta makanan yang kurang beragam, adekuat/cukup, dan aman sesuai dengan rekomendasi Kementerian Kesehatan dan IDAI.

Hasil wawancara dengan Ketua Pengurus PKK juga mengungkap bahwa selama ini, para ibu umumnya memberikan nutrisi pada anak sesuai dengan pola asuh yang biasa dilakukan di masyarakat atau berdasarkan masukan dari provider kesehatan masingmasing. Mitra juga belum pernah mendapatkan kegiatan parenting dalam bentuk apapun (termasuk parenting gizi) baik itu dari pihak Pemerintah, Perguruan Tinggi, maupun Swasta.

Upaya monitoring pertumbuhan balita biasanya dilakukan mitra saat menghadri Posyandu yang dilaksanakan secara rutin setiap bulannya. Namun, kegiatan ini juga belum didukung dengan pemberian edukasi atau parenting secara khusus kepada seluruh ibu yang hadir tentang promosi gizi seperti pemberian ASI Ekslusif, MP-ASI, perbaikan pola asuh dan sebagainya. Kegiatan Posyandu yang sering dilaksanakan pada hari kerja juga menjadi faktor penghalang bagi ibu pekerja untuk turut hadir di Posyandu, sehingga tidak semua ibu di lingkup PKK Perum Tlanakan Indah bisa menghadiri kegiatan posyandu secara rutin. Terlebih, pada situasi pandemi Covid-19 kegiatan posyandu di Perum Tlanakan Indah masih belum dilaksanakan kembali. Atas kondisi ini, para ibu umumnya memilih untuk mengunjungi praktik Bidan Desa atau Puskesmas terdekat terutama untuk mendapatkan imunisasi pada balitanya.

Kondisi tersebut menunjukkan bahwa ibu-ibu yang tergabung dalam kelompok PKK Perum Tlanakan Indah belum mendapatkan informasi yang mencukupi dan belum memiliki pengetahuan yang mendalam untuk mengoptimalkan 1000 HPK. Oleh karenanya, kegiatan penyuluhan berupa parenting gizi berbasis WhatsApp perlu dilakukan untuk meningkatkan pengetahuan ibu dalam mengoptimalkan 1000 HPK.

Aplikasi WhatsApp (WA) dipilih sebagai media penyuluhan karena WA merupakan salah satu media sosial yang paling banyak digunakan oleh masyarakat serta memiliki fitur diskusi dalam grup yang dapat mendukung terjadinya interaksi antar anggota di dalamnya. Penyuluhan yang dilaksanakan melalui grup WA juga memungkinkan setiap peserta untuk mengakses materi dan diskusi tanpa dibatasi oleh ruang dan waktu. Kegiatan yang dilaksanakan melalui WA dengan demikian tidak memerlukan pertemuan secara langsung, sehingga dirasa sangat ideal untuk mendukung upaya pemerintah dalam mengurangi angka penyebaran Covid-19 yang masih mengalami peningkatan baik secara regional daerah maupun lingkup nasional. 
Berdasarkan penjelasan tersebut di atas, maka kegiatan pengabdian kepada masyarakat ini bertujuan untuk meningkatkan pemahaman ibu dalam mengoptimalkan 1000 HPK. Dengan demikian diharapkan kegiatan yang dilakukan ini dapat menjadi upaya promotif dan preventif masalah gizi di masyarakat melalui optimalisasi 1000 HPK.

\section{METODE KEGIATAN}

Program pengabdian pada masyarakat (PPM) yang dilaksanakan pada kegiatan ini melibatkan kelompok PKK Perum Tlanakan Indah RT 02 yang beranggotakan 40 peserta. Metode pemberdayaan masyarakat yang dilaksanakan yaitu berupa pendidikan masyarakat dengan cara memberikan penyuluhan berbasis WhatsApp (WA) untuk meningkatkan pengetahuan Ibu dalam mengoptimalkan 1000 Hari Pertama Kehidupan (1000 HPK). Pelaksanaan kegiatan parenting gizi berbasis WA dilaksanakan dalam 4 tahapan dengan total lama pelaksanaan selama 1 bulan (Tabel 1). Keempat tahapan tersebut yaitu:

- Tahap 1: Analisis situasi dan inisiasi kegiatan parenting dengan pengurus PKK yang meliputi kegiatan perkenalan, sharing pengalaman dan informasi tentang pemenuhan gizi anak di 1000 HPK, serta pembentukan WA group sebagai media pelaksanaan kegiatan.

- Tahap 2: parenting gizi berbasis WhatsApp. Pada tahap ini peserta memperoleh informasi dan diskusi seputar pemenuhan gizi pada 1000 HPK secara berkelanjutan.

- Tahap 3: kegiatan pendampingan untuk mendukung keberhasilan program.

- Tahap 4: evaluasi kegiatan untuk mengetahui keberhasilan program pengbadian pada masyarakat yang telah dilakukan dari awal hingga akhir kegiatan.

Tabel 1. Pelaksanaan Kegiatan

\begin{tabular}{|c|c|c|c|c|c|}
\hline \multirow{2}{*}{ Kegiatan } & \multicolumn{5}{|c|}{ Januari 2021} \\
\hline & 1 & 2 & 3 & 4 & 5 \\
\hline (1) Analisis Situasi & & & & & \\
\hline (2) Pelaksanaan & & & & & \\
\hline (3) Pendampingan & & & & & \\
\hline (4) Evaluasi & & & & & \\
\hline
\end{tabular}

Untuk mengoptimalkan pengukuran terhadap keberhasilan program, dilakukan pengumpulan data melalui penyebaran angket yang dikembangkan oleh penulis. Angket berisikan pertanyaan terkait data demografi serta pengetahuan mengenai optimalisasi gizi di 1000 HPK. Data mengenai tingkat pengetahuan peserta terkait 1000 HPK dilakukan pada saat sebelum (pretest) dan setelah kegiatan dilakukan (posttest). Dengan memperhatikan segi kepraktisan dan keamanan selama pandemi Covid-19, pengisian angket menggunakan platform Google Form kemudian disebarkan melalui grup WA kegiatan parenting. Data pretest dan postest yang terkumpul selanjutnya dianalisis dengan 
menghitung nilai gain score yang dinormalisasi ( $\mathrm{N}$-gain) berdasarkan persamaan oleh Hake \& Richard dalam Ramadani [7] sebagai berikut.

$$
\% \text { gain }=\frac{\text { skor postest-skor pretest }}{\text { skor maksimum }- \text { skor pretes }} \times 100 \%
$$

Tabel 2. Kriteria Skor Gain Ternormalisasi

\begin{tabular}{cc}
\hline Indeks N-gain & Kriteria \\
\hline$>0,70$ & Tinggi \\
\hline $0,30<\mathrm{g} \leq 0,70$ & Sedang \\
\hline$\leq 0,30$ & Rendah \\
\hline
\end{tabular}

\section{KARYA UTAMA}

Kegiatan PPM ini bertujuan untuk meningkatkan pengetahuan ibu dalam mengoptimalkan 1000 HPK. Kegiatan ini dihadiri dan diikuti oleh sebanyak 36 peserta (90\%) dari 40 anggota PKK. Dari jumlah peserta yang mengikuti kegiatan, sebanyak $33,33 \%$ diantaranya memiliki balita dan 5,5\% sedang menjalani masa kehamilan. Peserta juga terdiri atas $61,11 \%$ Ibu Rumah Tangga (IRT) dan 38,89\% sisanya adalah ibu pekerja (Gambar 1).
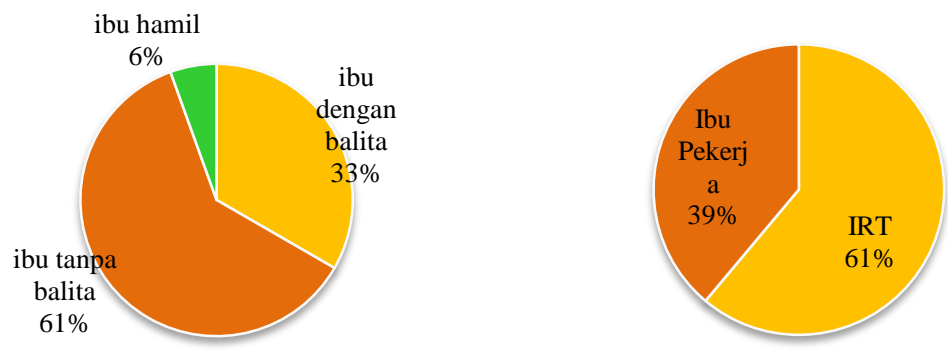

Gambar 1. Gambaran data demografi peserta parenting.

Selama kegiatan parenting, peserta memperoleh berbagai pengetahuan baru mengenai optimalisasi gizi pada ibu dan balita untuk mendukung 1000 HPK. Informasi yang disampaikan antara lain tentang kebutuhan nutrisi dan dukungan bagi anak sejak dalam kandungan hingga balita, termasuk informasi dan panduan tentang menyusui, pemberian makanan pendamping ASI (MPASI) bagi balita, serta konsep makan secara umum.

Materi penyuluhan disampaikan dengan bahasa yang mudah dipahami oleh peserta dengan mengkombinasikan antara pesan teks, gambar, dan juga video sehingga lebih menarik dan berkesan bagi para peserta. Setelah materi dibagikan, peserta diberikan waktu untuk mempelajari materi dan mempersiapkan pertanyaan untuk dilanjutkan pada sesi diskusi di hari berikutnya.

Selama kegiatan diskusi, antusiasme peserta sangat tinggi yang ditunjukkan dengan banyaknya peserta yang bertanya ataupun memberikan tanggapan terhadap pertanyaanpertanyaan yang muncul. Di akhir sesi sharing dan diskusi, para peserta juga diberikan 
kesempatan untuk menyampaikan pengalaman serta pesan dan kesan selama mengikuti kegiatan parenting.

Hasil pengukuran terhadap pemahaman awal dan akhir peserta kegiatan parenting ditunjukkan pada Tabel 2. Berdasarkan hasil analisis gain score tersebut, terjadi peningkatan pengetahuan peserta sebesar $82,22 \%$ atau dalam kategori sedang. Respon yang diberikan peserta di akhir kegiatan juga menunjukkan bahwa sebanyak 32 ibu dari total 36 peserta atau sebanyak 94,44\% peserta yang mengikuti parenting menyatakan setuju bahwa kegiatan ini telah meningkatkan pengetahuan mereka dalam upaya mengoptimalkan $1000 \mathrm{HPK}$.

Tabel 2. Perbandingan rerata skor pengetahuan peserta antara sebelum dan setelah pelaksanaan kegiatan PPM

\begin{tabular}{cccc}
\hline \multicolumn{2}{c}{ Rerata Skor Pengetahuan } & \multirow{2}{*}{ N-Gain (\%) } & Kategori \\
\cline { 1 - 2 } Awal & Akhir & & \\
\hline 45,28 & 81,39 & 82,22 & Sedang \\
\hline
\end{tabular}

\section{ULASAN KARYA}

Setiap anak berhak atas perkembangan perilaku kognitif, sosial, dan emosional yang optimal. Bagian kognitif, sosial, dan emosional otak terus berkembang sepanjang umur. Namun, sebagian besar dari struktur dan kapasitas utama otak dibentuk sejak 1000 HPK atau masa selama anak berada dalam kandungan hingga berusia 2 tahun. Oleh karenanya, periode penting ini disebut sebagai periode emas. Kegagalan untuk mengoptimalkan perkembangan otak di awal kehidupan akan berdampak terhadap pertumbuhan otak sehingga anak tidak cerdas, terjadi kegagalan pertumbuhan/ stunting, anak menjadi lemah dan mudah sakit [3], serta konsekuensi jangka panjang yang turut mempengaruhi pendidikan, potensi pekerjaan, dan kesehatan mental di masa dewasa [1] [8] (lihat Gambar 2).

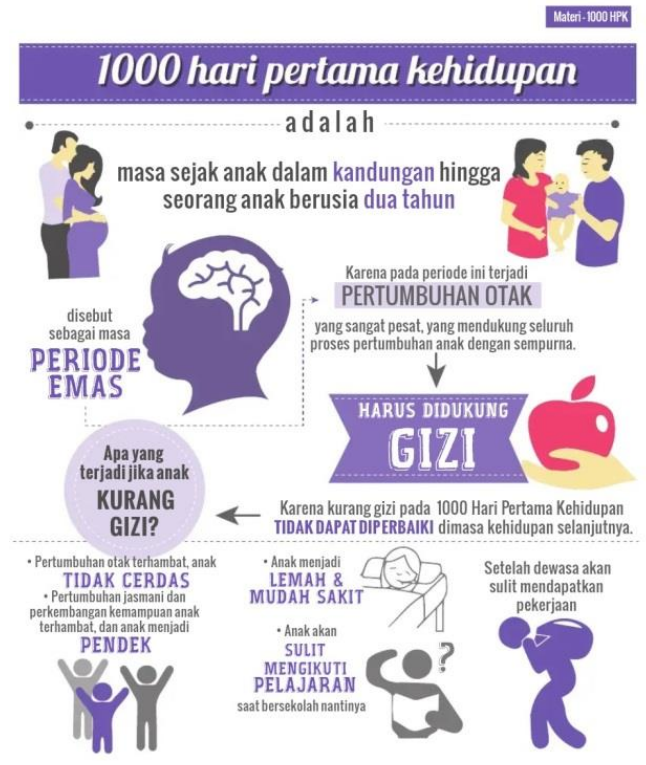

Gambar 2. Pentingnya 1000 HPK [3] 
Berbagai laporan penelitian menyebutkan bahwa dua faktor utama yang memberikan dampak sangat besar terhadap perkembangan awal otak yaitu adanya dukungan sosial yang kuat dan penyediaan nutrisi yang optimal, sementara faktor lainnya yaitu adanya pengaruh infeksi atau inflamasi [2][8][9]. Sejalan dengan hal tersebut, kegiatan PPM yang dilaksanakan, memfokuskan kegiatan melalui edukasi seputar gizi disertai pola asuh yang sesuai untuk mendukung optimalisasi 1000 HPK.

Agar kebutuhan gizi di 1000 HPK terpenuhi untuk mendukung tumbuh kembang yang optimal pada anak, maka harus dipastikan bahwa kehamilan seorang ibu berjalan baik sampai kelahiran bayi. Demikian pula, bayi mendapatkan nutrisi terbaik dan stimulasi yang sesuai untuk mendukung tumbuh kembangnya. Kebutuhan gizi bayi di usia 0-6 bulan dapat dipenuhi secara sempurna melalui pemberian ASI; sedangkan setelah usia 7 bulan, kandungan gizi pada ASI tidak lagi mencukupi kebutuhan bayi sehingga perlu diberikan makanan tambahan pendamping ASI (MPASI) (lihat Gambar 3).

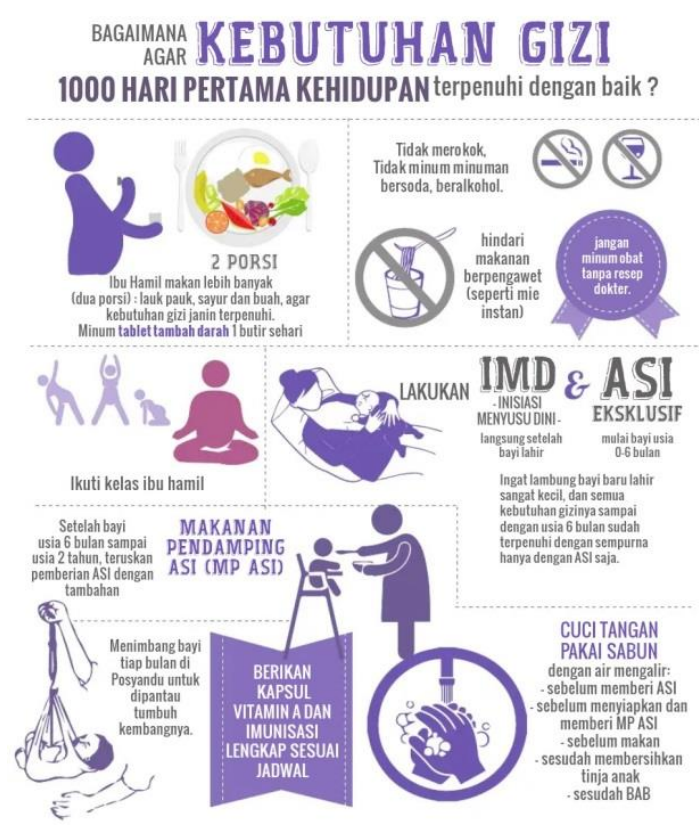

Gambar 3. Cara Mencukupi Kebutuhan Gizi di 1000 HPK [3]

Salah satu permasalahan yang dihadapi mitra dalam upaya pemenuhan gizi anak melalui pemberian ASI secara ekslusif antara lain yaitu persepsi ibu bahwa ASI tidak keluar, ASI sedikit, anak menolak ASI, ataupun kondisi ibu pekerja yang tidak dapat menyusui. Ketakutan ibu bahwa bayinya akan kekurangan gizi karena kondisi ini menjadi faktor pendorong bagi ibu untuk menyerah memberikan ASI dan beralih memberikan susu formula tanpa indikasi medis yang ditentukan oleh dokter, bidan, ataupun perawat. Sayangnya, fenomena semacam ini rupanya juga banyak terjadi dan menjadi faktor utama yang berkontribusi terhadap angka menyusui di banyak negara maju tetap rendah [10].

Berbagai organisasi kesehatan menjelaskan bahwa menyusui adalah cara yang paling ideal untuk memberikan nutrisi bagi bayi [11]. Kewajiban untuk memberikan ASI Ekslusif pada 6 bulan pertama sejak kelahiran juga telah diatur dalam Peraturan Pemerintah (PP) 
No. 33/2012 tentang pemberian ASI Ekslusif [12]. Hal ini tidak lepas dari berbagai manfaat jangka pendek maupun jangka panjang pemberian ASI bagi anak maupun ibu (lihat Gambar 4).

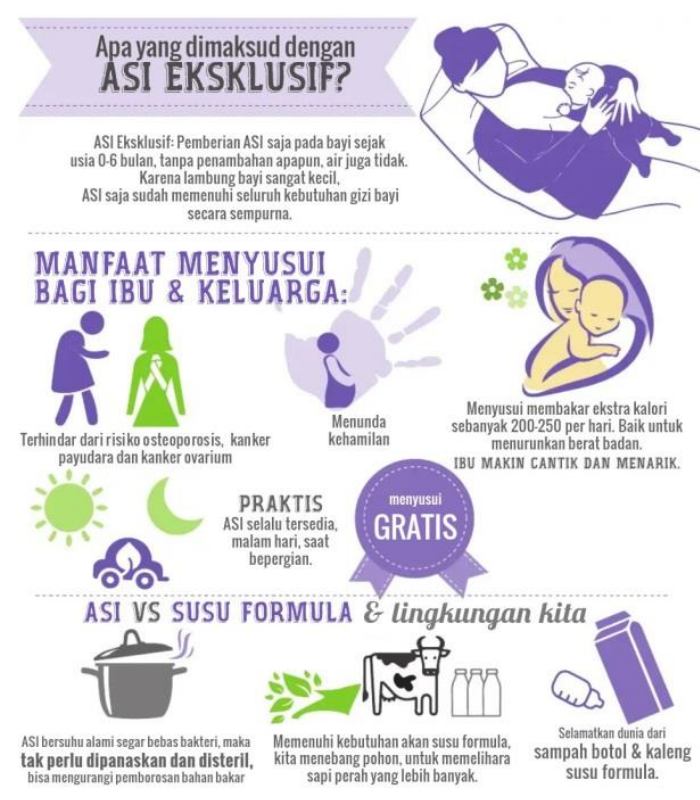

Gambar 4. Manfaat Menyusui Bagi Ibu dan Keluarga

ASI secara alamiah dihasilkan oleh ibu selepas persalinan dan dapat ditingkatkan produksinya melalui teknik dan manajemen menyusui. Dengan demikian tidak mengherankan jika edukasi menyusui sangat penting diberikan kepada calon ibu demi keberhasilan menyusui di masa berikutnya. Hal ini terbukti dari hasil penelitian Rosen [11] bahwa wanita yang memperoleh edukasi menyusui sebelum masa kehamilan mengalami peningkatan keberhasilan menyusui secara signifikan pada 6 bulan pertama jika dibandingkan dengan kontrol. Bahkan, hasil studi tersebut juga mengungkap bahwa tidak ada perbedaan yang signifikan antara cara edukasi yang diberikan terhadap keberhasilan menyusui. Chapman, et al [13] juga menemukan bahwa konselor sebaya pada masa postpartum mampu meningkatkan keberhasilan menyusui pada 1 dan 3 bulan setelah persalinan.

Informasi mengenai cara mengatasi hambatan pemberian ASI karena persepsi ibu bahwa asi tidak keluar atau asi sedikit juga telah disampaikan pada saat kegiatan parenting. Para ibu diberikan pemahaman bahwa prinsip untuk menjaga ataupun meningkatkan produksi ASI sangat bergantung pada seberapa sering ibu melakukan pengosongan payudara. Pengosongan payudara dapat dilakukan ibu dengan menyusui anak sesering mungkin maupun dengan memompa ASI. Kent \& Garbin [10] menyebut bahwa para ibu disarankan untuk menyusui 8 sampai $12 \mathrm{kali} /$ hari untuk membentuk dan mempertahankan produksi ASI. Bayi yang disusui eksklusif rata-rata menyusu selama delapan sesi menyusui/ hari tetapi bisa juga berkisar dari 4 hingga 13 sesi menyusui/hari. Dengan demikian, Ibu pekerja dapat mengikuti frekuensi memompa seperti sesi menyusui alami untuk tetap mempertahankan produksi ASI, yaitu total sebanyak 12 sesi, ditambah teknik 
power pumping saat dini hari. ASI hasil perah yang dihasilkan selanjutnya dapat diberikan kepada anak saat ditinggal bekerja.

Pengetahuan tentang cara perlekatan saat menyusui maupun cara memerah ASI yang tepat dan komitmen yang tinggi sangat diperlukan agar ibu berhasil meningkatkan produksi ASI-nya. Selain itu, dukungan dari orang sekitar termasuk keluarga dekat sangat dibutuhkan.

Setelah bayi mencapai usia 6 bulan, maka anak memerlukan tambahan makanan selain ASI (MPASI) (lihat Gambar 5). Ikatan Dokter Anak Indonesia [14] merekomendasikan besarnya energi tambahan dari MPASI adalah sebanyak 200 kilo kalori (kkal) per hari pada usia 6-9 bulan, 300 kkal pada usia 9-12 bulan, dan 550 kkal pada usia 12-24 bulan. Pemberian MPASI juga harus tepat dengan memperhatikan prinsip ketepatan waktu, kecukupan, keamanan, dan penyajian yang tepat seperti yang disarankan oleh World Health Organization (WHO) (Gambar 6).

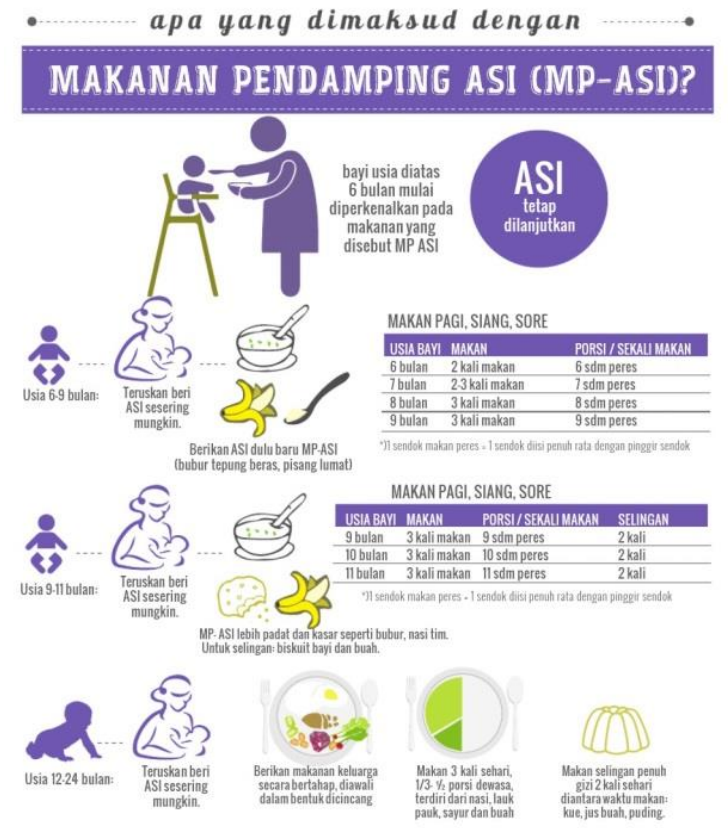

Gambar 5. Makanan Pendamping ASI (MPASI) untuk bayi di atas 6 bulan

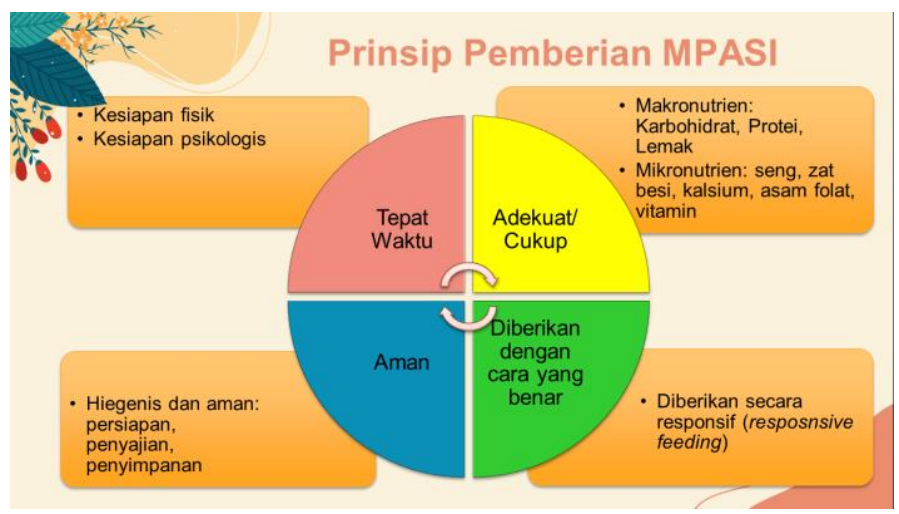

Gambar 6. Prinsip Pemberian MPASI 
Selain mencukupi gizi anak, peserta kegiatan juga dibekali informasi terkait pola asuh yang tepat, seperti disiplin dalam memantau pertumbuhan dan perkembangan anak, menerapkan pola hidup bersih dan sehat (PHBS), serta memberikan rangsangan/stimulasi dalam suasana yang menyenangkan sesuai dengan perkembangan bayi. Para ibu juga diberikan motivasi untuk membaca buku KIA bahkan sebelum bayi lahir agar pemahaman mengenai tumbuh kembang anak semakin baik.

\section{DAMPAK DAN MANFAAT KEGIATAN}

Para ibu yang telah ditingkatkan pengetahuannya mengenai pemenuhan gizi anak selama periode emas ini diharapkan dapat mengembangkan keterampilan dalam mengasuh anak secara tepat terutama selama 1000 HPK untuk meningkatkan kualitas kehidupan generasi yang akan datang.

\section{KESIMPULAN}

Melalui pelaksanaan proram PPM ini telah dicapai beberapa hal positif terutama dalam upaya memecahkan permasalaham mitra dalam meningkatkan pengetahuan ibu mengenai pentingnya gizi dalam mengoptimalkan program $1000 \mathrm{HPK}$.

Hasil PPM menunjukkan bahwa melalui kegiatan parenting gizi berbasis WhatsApp, pengetahuan ibu mengenai optimalisasi 1000 HPK meningkat sebesar 82,22\% atau dalam kategori sedang. Kegiatan semacam ini juga berhasil meningkatkan kepercayaan diri ibu dalam memberikan pengasuhan secara tepat untuk mendukung tumbuh kembang anak.

Upaya mendukung optimalisasi 1000 HPK untuk tumbuh kembang anak adalah peran banyak pihak, tidak hanya orang tua, tenaga kesehatan, kader posyandu, guru, dan masyarakat umum. Oleh karenanya, maka saran pengembangan yang dapat diusulkan yaitu agar kegiatan sejenis perlu terus ditingkatkan. Bagi pihak terkait, terutama bagi Puskesmas agar dapat memberikan parenting melalui Posyandu di wilayah kerjanya guna mendukung optimalisasi 1000 HPK.

\section{DAFTAR PUSTAKA}

[1] E. L. Prado and K. G. Dewey, "Nutrition and brain development in early life," Nutr. Rev., vol. 72, no. 4, pp. 267-284, 2014, doi: 10.1111/nure.12102.

[2] S. J. Schwarzenberg and M. K. Georgieff, "Advocacy for improving nutrition in the first 1000 days to support childhood development and adult health," Pediatrics, vol. 141, no. 2, 2018, doi: 10.1542/peds.2017-3716.

[3] Kementerian Kesehatan RI, "Keluarga Sehat Idamanku, Kota Sehat Kotaku,” 2014.

[4] J. Manuel and M. Villares, "Nutrición Hospitalaria," vol. 33, pp. 8-11, 2016.

[5] Pedoman Perencanaan Program Gerakan Nasional Percepatan Perbaikan Gizi 
dalam Rangka Seribu Hari Pertama Kehidupan (Gerakan 1000 HPK). 2013.

[6] D. A. Hoffmann, J. M. Marx, A. Kiefner-Burmeister, and D. R. Musher-Eizenman, "Influence of maternal feeding goals and practices on children's eating behaviors," Appetite, vol. 107, pp. 21-27, 2016, doi: 10.1016/j.appet.2016.07.014.

[7] A. Ramadani, Shefa Dwijayanti; Budiyono, "PENINGKATAN PEMAHAMAN KESEHATAN REPRODUKSI DALAM BINGKAI ISLAM BAGI SISWA SEKOLAH DASAR DI DESA," Pros. Semin. Nas. Pengabdi. Masy., vol. 2, no. 1, pp. 261-266, 2018, [Online]. Available: http://senias.uim.ac.id/index.php/senias_2017/article/view/178.

[8] S. E. Cusick and M. K. Georgieff, "The Role of Nutrition in Brain Development: The Golden Opportunity of the 'First 1000 Days," J. Pediatr., vol. 175, pp. 16-21, 2016, doi: 10.1016/j.jpeds.2016.05.013.

[9] K. G. Dewey and D. R. Mayers, "Early child growth: How do nutrition and infection interact?," Matern. Child Nutr., vol. 7, no. SUPPL. 3, pp. 129-142, 2011, doi: 10.1111/j.1740-8709.2011.00357.x.

[10] I. Demand, "Human Lactation,” 2013, doi: 10.1177/089033449501100119.

[11] I. M. Rosen, M. V Krueger, L. M. Carney, and J. A. Graham, "BASELINE," no. October 2008, pp. 315-319.

[12] PERATURAN PEMERINTAH REPUBLIK INDONESIA NOMOR 33 TAHUN 2012 TENTANG PEMBERIAN AIR SUSU IBU EKSKLUSIF. .

[13] D. J. Chapman, G. Damio, S. Young, and R. Pérez-Escamilla, "Effectiveness of breastfeeding peer counseling in a low-income, predominantly Latina population: A randomized controlled trial," Arch. Pediatr. Adolesc. Med., vol. 158, no. 9, pp. 897902, 2004, doi: 10.1001/archpedi.158.9.897.

[14] IDAI, "Pemberian Makanan Pendamping Air Susu Ibu (MPASI)," UKK Nutrisi dan Penyakit Metabolik IDAI. p. 18, 2018. 